\title{
Tax Rate Harmonization, Renegotiation and Asymmetric Tax Competition for Profits with Repeated Interaction
}

\author{
Wolfgang Eggert* Jun-ichi Itaya ${ }^{\dagger}$
}

March 17, 2014

\begin{abstract}
This paper analyzes a model of corporate tax competition with repeated interaction and with strategic use of profit shifting within multinationals. We show that international tax coordination is more likely to prevail if the degree of asymmetry in terms of productivity differences between countries is smaller, or if concealment costs of profit shifting are larger when the tax authorities adopt grim-trigger strategies. Allowing for renegotiation in the tax harmonization process generally requires more patient tax authorities to support tax harmonization as a subgame perfect equilibrium. We find somewhat paradoxical situations where higher costs of profit shifting may make international tax arrangements less sustainable under weakly-renegotiation-proof strategies.
\end{abstract}

Keywords: corporate taxation, profit shifting, tax coordination, multinational firms

JEL classifications: $\mathrm{H} 25, \mathrm{H} 87, \mathrm{~F} 23$

*Albert-Ludwigs-University Freiburg, CESifo and ifo Institute for Economic Research at the University of Munich, Bertoldstr. 17, 79098 Freiburg, Germany. Tel: +49-0761203-2358; E-mail: wolfgang.eggert@vwl.uni-freiburg.de

${ }^{\dagger}$ Corresponding author. Graduate School of Economics and Business Administration, Hokkaido University, Kita 9, Nishi 7, Sapporo, 060-0809, JAPAN. Tel: +81-11-706-2858; fax: +81-11-706-4947. E-mail address: itaya@econ.hokudai.ac.jp. 


\section{Introduction}

The taxation of income of multinational firms and the proper assignment of the 'fiscal common' (Konrad, 2008) to individual countries has been a long-standing issue in both policy and academic debates. Concerns about the definition of a 'fair' share of the corporate tax base (corporate income or profits) are strong in the European Union and elsewhere; hence design of an internationally appropriate corporate tax system is a major issue in the literature on tax competition.

Existing corporate tax systems make the fundamental assumption that calculation of profits is conceptually meaningful (e.g., Meade Committee, 1978). Thus they permit the deduction of costs from revenue to calculate the tax base. This treatment of costs offers firms a fundamental incentive to overstate costs as a means to reduce taxable rents or profits. In federations the same economic argument creates additional challenges for operational tax design since tax planning strategies of a firm operating in several states (i.e., multi-state-firms) not only make the sum of true economic profits private information, but also the observed profit allocation across jurisdictions is endogenous to the taxes chosen by states (see, e.g., Mintz and Smart, 2004). To limit competition for mobile tax bases and to sustain a desired level of regional cohesion or cooperation between regions, federal states as the United States, Canada and Germany traditionally implicitly distribute the tax base between jurisdictions through (apportionment) formulas, or introduced explicit interregional transfers. In an open economy, similar mechanisms are relevant on the firm level and there is ample evidence by now that firms operating in more than one country (i.e., multinational firms) shift profits to reduce the overall tax burden. The reaction of policy, however, is notoriously more complicated compared to federations, as countries fiercely defend their sovereignty.

The arrangement we analyze is a two-country world where countries host a multinational firm. The multinational firm makes a factor employment decision and chooses the transfer price for an intermediate good to maximize net of tax profits. There are many explanations for profit shifting that have been proposed in the literature; see, e.g., Devereux and Sørensen (2005), Huizinga, Laeven, and Nicodème, (2008), Huizinga and Laeven (2008). 
We also consider tax authorities in the two countries which choose their tax rates on book profits non-cooperatively over an infinite time horizon. We abstain from symmetry assumptions to get a situation where tax authorities non-cooperatively choose different tax rates. Divergent statutory tax rates cause profit shifting. Against this background, there have in fact been attempts in the past to coordinate corporate income taxation in the EU, but most proposals failed since they did not get unanimous approval by the Council. See Brøchner, Jensen, Svensson and Sørensen (2006). The reluctance of the Commission to interfere in national company taxation seems to be at least partly influenced by its weak position in direct tax harmonization. The harmonization of capital taxation has to be based on Art. 100, which allows for a mandatory adjustment of national legislation in order to back the functioning of the internal market. The political constraints on Commission initiatives in capital taxation have not been relaxed by the Maastricht Treaty.

Often measures of tax harmonization have been advocated to limit strategic choice of taxes by individual countries. ${ }^{1}$ Hence, there is an important question on whether when enforcement by the third parties is not possible, the EU member state may tacitly agree to coordinate their tax rates, or voluntarily reach explicitly contractual agreements in a treaty on measures of tax harmonization. ${ }^{2}$ This is so because the lack of external enforcement which usually holds for such an international agreement induces each country or signatory to have an incentive to free ride on others signing the tax treaty. In other words, the treaty should be a self-enforcing agreement in the sense that no country can be forced to sign an agreement and signatories cannot be forced to comply with the agreement.

As Wilson (1991) has shown, in the absence of profit shifting, it may be possible that potential gains from competition are comparatively large for the small country. He concludes that only a few and very small countries can

\footnotetext{
${ }^{1}$ Griffith, Hines, and Sorensen (2008) give excellent account of the recent literature on capital tax competition.

${ }^{2}$ In politics famous examples for common-pool problems exist as the current efforts to establish international information sharing agreements between tax authorities shows (consider the OECD blacklist as a punishment device). It seems today that an agreement (implicit cullusion of tax authorities) is within reach here. The EU Stability and Growth Pact was created to enforce budgetary discipline among EU member states. It is currently under renegotiation. The Kyoto Protocol aims to reduce global greenhouse gas emissions by implementing legally binding agreements.
} 
benefit from tax competition and that an agreement to coordinate tax rates is possible. Unfortunately, this conclusion may not be true. Although such tax coordination (harmonization) among all countries would be desirable or Pareto-improving compared to a Nash tax competition equilibrium, it may not be possible to achieve it, because the structure of payoffs accrued to jurisdictions displays characteristics of 'Prisoner's dilemma' where the Pareto efficient outcome is not an equilibrium in a one-shot tax competition game. This possibility is highly likely to occur in tax competition models mainly due to a positive fiscal externality associated with regional tax policies (see Wildasin, 1989).

On the other hand, the theory of repeated games has demonstrated that repeated interactions between policy makers which allow for punishment in future periods may lead to the emergence of voluntary cooperation even in the absence of a super-national tax authority. Under only an implicit coordination mechanism (explicit self-enforcing contractual agreements in a treaty), voluntary participating countries (signatories singing a treaty) have an incentive to act in accordance with tacit collusion (the treaty obligations). This paper deals with the scope of long-run cooperation among noncooperative tax authorities which are willing to achieve and sustain tax harmonization when repetition is allowed but enforcement by third parties does not exist. Cardarelli et al. (2002), Catenaro and Vidal (2006), and Itaya et al. (2008, 2010) have investigated the likelihood of tax harmonization among non-cooperative governments which use grim-trigger strategies in the infinitely repeated tax competition game. Nevertheless, in spite of the growing importance of foreign direct investment through multinational firms mentioned earlier, none of these authors has considered profit shifting activities of multinational firms so far, which is the main aim of the present paper where we incorporate competition for shifty profits of multinational firms into a repeated game framework of asymmetric corporate tax competition.

Another novelty of the present analysis is to permit a characterization of the way that equilibria under the weakly renegotiation-proof (WRP in what follows) as well as grim-trigger strategies of infinitely repeated games. In addition to the unrealistic nature of infinitely repeated punishment associated with grim strategies and the fact that the existing tax competition literature 
has not addressed WRP strategies so far, there are several compelling reasons to consider WRP strategies in the context of tax competition. First, WRP equilibria are a subset of subgame perfect equilibria. Since the Folk theorem implies that as long as players are sufficiently patient, any outcome can be realized as a subgame perfect equilibrium. Hence, WRP equilibria would improve the predictability of the theory by eliminating some of subgame perfect equilibria. Second, renegotiation definitely plays a key role in international policy coordination issues such as measures of tax harmonization, because policy markers can usually communicate and make proposals every period they want. If communication is allowed, players cannot get rid of the incentives for renegotiation. In other words, in international negotiations and bargaining grim-trigger strategies which hurt the punisher as well as the punished forever are no longer creditable. In contrast, WRP strategies allow for a resumption of cooperation after punishment follows deviating behavior, which makes such strategies immune against renegotiation. As a result, WRP requires that the sum of all discounted present and future payoffs that the strategies give is not Pareto dominated by another strategy specification (Farrell and Maskin, 1989).

We show that the negative effect of country asymmetric (in terms of productivity of the affiliate located in each country) on the likelihood of tax harmonization prevails irrespective of which strategies are adopted. Although this is consistent with the result of Cardarelli et al. (2002) in the repeated tax competition game without multinational firms and profit shifting, the opportunity of profit shifting plays a key role in determining the sustainability of tax harmonization in our tax competition model.

This paper also differs from previous studies in that it analyzes exogenous changes in concealment costs for profit shifting affects the sustainability of tax harmonization under grim-trigger and WRP strategies. Under trigger strategies (i.e., renegotiation is not allowed) higher concealment costs enhance the sustainability of tax harmonization, while under WRP strategies (i.e., renegotiation is allowed) the result depends on the level of cooperative tax rate. That is, if this tax rate is set at lower levels, tax harmonization is hampered by higher concealment costs, while if this tax rate is set at higher levels, the result is reversed. 
The reminder of the paper is organized as follows. Section 2 presents a simple model of asymmetric tax competition for the profits of a multinational firm and characterizes the cooperative solution as a target tax rate at which governments are coordinated. Grim-trigger strategies in tax policy are analyzed in Section 3 and the outcome with WRP strategies is central in Section 4. Section 5 undertakes several extensions of the basic model presented in Section 6. Mathematical details are relegated to appendices.

\section{The model}

We consider two countries $i=1,2$ which are inhabited by a large number of investors endowed with $\bar{k}$ units of capital. In each period these investors allocate their capital internationally to finance investment of a multinational firm operating in the two countries. The multinational firm maximizes the discounted sum of profits net of the corporation tax through the choice of factor employment and strategic manipulation of declared costs over an infinite number of periods. The tax authority in each country tries to combat profit shifting through cost manipulation, but is restricted to a source tax on book profits.

\subsection{Technologies}

Production technologies. The multinational firm seeks $k_{i}$ units of per capita capital and an essential service to produce output in each period. For analytical convenience, we treat the size of the essential service, such as labor inputs, fixed at unity (Riedel and Runkel, 2007). The affiliate of the multinational firm in country $i$ has a technology described by the strictly concave, constant-returns-to-scale production function (Bucovetsky, 1991; Haufler, 1997; Stöwhase, 2005; Peralta and Ypersele, 2006):

$$
f_{i}\left(k_{i}\right):=\left(A_{i}-k_{i}\right) k_{i}
$$

where the marginal productivity (of the first unit) of capital, $A_{i}$, may differ among (asymmetric) countries. We assume throughout that the marginal productivity of capital is positive, i.e., $A_{i}>2 k_{i}$. 
Profit-shifting technology. Self selection of firms into profit-shifting and the externalities caused thereby do play a central role in this analysis. Potential for profit shifting is arising because the multinational firm has better information as to the actual costs than the tax authority. The choice of the declared cost structure between affiliated entities creates possibilities to transfer profits between taxing jurisdictions. We shall argue that the true costs of the essential service are unity, $s=1$. Thus, a choice of $s>1$ implies overinvoicement and $s<1$ underinvoicement of the service. To limit strategic transfer pricing it seems natural to model the costs of misdeclaration by a convex function (see, e.g., Hauler and Schjelderup, 2000). In the analysis of repeated interaction below it will become necessary to compare directly the levels of profits in its cooperative and non-cooperative phases. To this end we specify that the costs of profit shifting are quadratic in the level of misdeclaration (see, e.g., Stöwhase, 2005; Kind, et al. 2005):

$$
q(s)=\frac{\beta}{2}(s-1)^{2} \quad \text { with } \quad \beta \geq 0 .
$$

The lower bound $\beta=0$ corresponds to complete or unhindered profit shifting and thus to complete or perfect spillovers of the activities of the multinational firm on the tax bases of countries.

\subsection{Institutions}

Although the multinational firms are operating over an infinite number of periods, due to the stationary assumption of a repeated game the same bookprofits of the multinational firm after the corporation tax is repeated in every period, that is: ${ }^{3}$

$$
\Pi:=\sum_{i=1}^{2} \pi_{i}-q(s)=\sum_{i=1}^{2}\left\{\left(1-\tau_{i}\right)\left[f_{i}\left(k_{i}\right)-r k_{i}+(-1)^{i}(s-1)\right]\right\}-q(s),
$$

\footnotetext{
${ }^{3}$ Alternatively, one could assume that the costs of misdeclaration are deductible from the tax base in one of the two countries or at some convex combination (see, e.g., Stöwhase, 2005). Although all these are noteworthy alternatives, Nielsen, Raimondos-Møller and Schjelderup (2009) check robustness and show that alternative modeling assumptions have an insignificant effect on outcome.
} 
where $r$ is the world-market rental rate per unit of capital and $\tau_{i}$ denotes the tax rate levied on corporate profits in country $i$, and where $\pi_{i}$ represents the tax base faced by the tax authority of country $i$.

Due to the stationary environment of repeated games the multinational firm also chooses the same values of $k_{i}$ and $s$ repeatedly to maximize (3) in every period, given the tax rates $\tau_{i}, i=1,2$. Choices are characterized by the first-order conditions (recall $A_{i}>2 k_{i}$ ):

$$
\begin{aligned}
\frac{\partial f_{i}\left(k_{i}\right)}{\partial k_{i}} & =A_{i}-2 k_{i}=r, \quad i=1,2, \\
\frac{\partial q(s)}{\partial s} & =\beta(s-1)=\tau_{1}-\tau_{2} .
\end{aligned}
$$

Denote in the following by $\theta:=A_{1}-A_{2}$ the difference in productivities between the affiliates of the multinational firm. Let $\theta \geq 0$ in what follows without loss of generality.

We first assume that tax authorities are maximizing the discounted sum of tax revenues over an infinite number of periods:

$$
V_{i}=\sum_{t=0}^{\infty} \delta^{t} R_{i}, \quad i=1,2
$$

where $\delta \in(0,1)$ is the common (actual) discount factors possessed by the tax authorities of the respective countries. This assumption is commonly applied in the existing literature. ${ }^{4}$ The one-shot tax revenue in country $i$ is

$$
\left.R_{i}\left(r, \tau_{1}, \tau_{2}\right):=\tau_{i}\left[f_{i}\left(k_{i}\right)-r k_{i}+(-1)^{i}(s-1)\right)\right], \quad i=1,2 .
$$

\subsection{Capital market equilibrium}

A market equilibrium in each period is a world rental rate $r$ such that in each period equity holders choose their place of investment to maximize income

\footnotetext{
${ }^{4}$ E.g., Elitzur and Mintz (1996), Mansori and Weichenrieder (2001) and Stöwhase (2005) among many others. In some of the existing literature this assumption is defended on the ground of political economy arguments as governments want to support the working population against the perceived wage decrease caused by globalization. Others argue that governments place a low weight on consumer or producer rents.
} 
and the capital market clears:

$$
k_{1}(r)+k_{2}(r)=2 \bar{k}
$$

where $k_{i}(r)$ represents the capital demand function of the multinational's affiliate located in country $i$. Substituting out for $k_{i}$ in (7) using (4) gives the world market rental rate for capital:

$$
r=\frac{1}{2}\left(A_{1}+A_{2}-4 \bar{k}\right)
$$

Substituting (8) back into $r$ in (4) gives the capital demand functions of the multinational firm:

$$
k_{i}=\frac{1}{4}\left[4 \bar{k}-(-1)^{i} \theta\right], \quad i=1,2
$$

where we assume $\theta \in[0,4 \bar{k})$ throughout in order to ensure strictly positive investment in both countries. Then use (1), (2), (5), the capital demand

functions (9) and the market rental rate (8) in the profit definition (3) to get the one-shot (global) profit of the multinational firm:

$$
\Pi=\frac{\left(\tau_{1}-\tau_{2}\right)^{2}}{2 \beta}+\sum_{i=1}^{2} \frac{\left(1-\tau_{i}\right)\left(r-A_{i}\right)^{2}}{4} .
$$

Substituting out for $k_{i}$ using (9), for $r$ using (8) and for $s$ using (5) in (6), the one-shot tax revenue function (6) becomes

$$
R_{i}:=\tau_{i} \pi_{i}=\tau_{i}\left[\frac{\left(\theta-(-1)^{i} 4 \bar{k}\right)^{2}}{16}+(-1)^{i} \frac{\tau_{1}-\tau_{2}}{\beta}\right], \quad i=1,2
$$

\section{$2.4 \quad$ Nash tax rates}

We first consider the tax authorities to act independently and noncooperatively in making their policy decisions over an infinite time horizon. The solution of the stage (or one-shot) game of the repeated game is a Nash equilibrium in setting tax rates:

$$
\tau_{i}^{N}:=\underset{\tau_{i}}{\arg \max } R_{i}\left(\tau_{i}, \tau_{j}^{N}\right), \quad i=1,2, i \neq j
$$


Note also that the infinite repetition of the one-shot Nash equilibrium tax rates, $\tau_{i}^{N}$, conform a subgame perfect equilibrium of the repeated game. Solving the first-order conditions for the tax rate gives

$$
\tau_{i}\left(\tau_{j}\right)=\frac{1}{32}\left[16 \tau_{j}+\beta\left(4 \bar{k}-(-1)^{i} \theta\right)^{2}\right], \quad i=1,2, i \neq j .
$$

Inspection of (12) shows that best responses satisfy $\partial \tau_{i}\left(\tau_{j}\right) / \partial \tau_{j}<1, i, j=$ 1,2 but $i \neq j$ (i.e., strategic complements in taxes), implying the existence of a unique Nash equilibrium in its stage game. The solution of (12) is

$$
\tau_{i}^{N}=\frac{1}{48} \beta\left[48 \bar{k}^{2}-(-1)^{i} 8 \bar{k} \theta+3 \theta^{2}\right], \quad i=1,2 .
$$

These tax rates reveal that - given that concealment costs are positive (i.e., $\beta>0$ ) - the more productive country (i.e., country 1 ) chooses to levy the tax at a higher rate than the less productive country (i.e., country 2 ). The difference in taxes vanishes in the absence of a difference in productivities (i.e., $\theta=0$ ); in other words, the presence of the difference in productivities induces non-cooperative governments to set different tax rates, which in turn motivates multinational firms to engage in profit shifting. Note also that decreasing the concealment costs (i.e., decreasing $\beta$ ) reduces the difference in taxes. This is consistent with the result of Stöwhase (2005) with heterogenous population in that profit shifting leads to a convergence of tax rates. Substituting (13) into (11) gives the one-shot Nash tax revenue:

$$
R_{i}^{N}=\frac{1}{2304} \beta\left[48 \bar{k}^{2}-8 \bar{k} \theta+3 \theta^{2}\right]^{2}, \quad i=1,2
$$

It is clearly straightforward that $R_{1}^{N}-R_{2}^{N}=(1 / 24) \beta \theta \bar{k}\left(\theta^{2}+16 \bar{k}^{2}\right)>0$, implying that tax revenues are higher in country 1 where the multinational's local affiliate has the more advanced technology, whereas the absence of such a difference (i.e., $\theta=0$ ) leads to equal tax revenues. We may then characterize the market rental rate and the allocation of capital as $r^{N}=r$ in (8) and $k_{i}^{N}=k_{i}, i=1,2$, in (9). The one-shot global profits of the multinational firm are

$$
\Pi^{N}=\frac{\theta^{2}}{8}-\frac{\beta \theta^{4}}{128}-2 \beta \bar{k}^{4}+\left(2-\frac{13 \beta \theta^{2}}{36}\right) \bar{k}^{2} .
$$


That $\partial \Pi^{N} / \partial \beta<0$ is intuitive; higher compliance (concealment) costs decrease profits in a noncooperative situation. It is also seen from (15) that profits are increasing in $\theta$ for low values of the compliance cost parameter $\beta$ and inverse $U$ shaped in $\theta$ for higher values of $\beta$. Thus profits are decreasing in $\theta$ in situations with high compliance costs. The economic argument here is that a high marginal compliance cost combined with a difference in productivity among affiliates imply that tax rates differ between countries, giving rise to profit shifting activities at the firm level to reduce the tax burden in the high-tax country. High marginal compliance costs reduce the profitability of profit shifting, allowing the high-tax country to cut into the profits of the multinational firm.

\subsection{Cooperative tax rates}

Although an infinite repetition of the Nash tax rates that prevail in the one-shot tax competition game constitutes a subgame perfect equilibrium of the repeated game, there is a possibility that governments may achieve a higher discounted sum of tax revenue by setting corporate tax rates in a cooperative manner. In the present model with a stationary economic environment the problem of finding the maximum of the discounted sum of joint tax revenues over an infinite time horizon simply amounts to infinite repetition of maximizing the one-shot joint tax revenue in all periods. The first-order conditions for maximizing the one-shot joint tax revenue $R_{1}^{C}+R_{2}^{C}$ are given by

$$
\begin{aligned}
r^{C} & =A_{i}-2 k_{i}, \quad i=1,2, \\
0 & =\tau_{1}-\tau_{2} .
\end{aligned}
$$

Condition (16) is the condition for the optimal use of capital. Condition (17) characterizes the tax rates needed to minimize the costs of profit shifting, i.e., minimum concealment costs. This requires equal tax rates, i.e., $\tau^{C}:=\tau_{i}$, $i=1,2$, though all periods, to eliminate a pure waste of resources associated with compliance costs. So one of the defining characteristics of harmonization measures is that taxes are set uniformly in our model. This is in accordance with much of the literature on fiscal decentralization within a system of 
asymmetric jurisdictions. Clearly, since the sum of tax revenues, $R_{1}^{C}+R_{2}^{C}$, is maximized at the upper bound of $\tau^{C}$, we set $\tau^{C}$ equal to this upper bound. We also assume that this upper bound is not confiscatory (i.e., $\tau^{C}<1$ ) due to the presence of institutional and political constraints such as lobbying by domestic producers. Such an upper bound is widely observed in practice and in many countries imposed by the constitution.

Using (8) and (9) that $r^{C}=r$ and $k_{i}^{C}=k_{i}, i=1,2$, gives the one-shot profits of the multinational firm:

$$
\Pi^{C}=\left(1-\tau^{C}\right) \frac{\theta^{2}+16 \bar{k}^{2}}{8}
$$

Profits are independent of concealment costs (i.e., the absence of $\beta$ ) since there does not exist any motive for profit shifting in the absence of tax rate differentials. In contrast, profits $\Pi^{C}$ are increasing in $\theta$, at least for non-confiscatory rates of the corporate tax. Making use of the common tax rate $\tau^{C}:=\tau_{i}, i=1,2$, in (11) yields the one-shot tax revenue under tax harmonization as

$$
R_{i}^{C}=\frac{\tau^{C}}{16}\left[\theta-(-1)^{i} 4 \bar{k}\right]^{2}, \quad i=1,2 .
$$

It is seen that $R_{1}^{C}-R_{2}^{C}=\tau^{C} \theta \bar{k}>0$. This implies that larger tax revenues accrue to the country where the more productive affiliate is located (i.e., country 1).

\section{Grim-trigger strategies}

Cooperation in tax policy requires that countries levy taxes at equal rates (i.e., tax harmonization) in all periods in order to avoid the resource costs of (wasteful) profit shifting activities. However, signing an agreement (or sustaining tacit collusion) that implements cooperation in tax setting is an economic activity which potentially is costly for an individual country. This means that a prerequisite (i.e., a necessary condition) to implement an agreement is the willingness of the national tax authorities to participate in the agreement.

Participation constraints. The participation constraints imply that coop- 
eration should give a higher tax revenue compared to the outcome with noncooperative behavior for each country in any period of time, i.e., $R_{i}^{C} \geq R_{i}^{N}$, $i=1,2$. Using (19) to substitute out for $R_{i}^{C}$ and (14) to substitute out for $R_{i}^{N}$, and solving for the equality gives the lower bounds $\underline{\tau}_{i}^{C}$ at which a country is indifferent between tax coordination and tax competition as

$$
\underline{\tau}_{i}^{C}=\frac{\beta}{144} \frac{\left[3 \theta^{2}-(-1)^{i} 8 \bar{k} \theta+48 \bar{k}^{2}\right]^{2}}{\left[\theta-(-1)^{i} 4 \bar{k}\right]^{2}}, \quad i=1,2 .
$$

It is straightforward to check that both lower bounds are $U$-shaped in $\theta \in$ $[0,4 \bar{k})$, where $\underline{\tau}_{i}^{C}=\beta \bar{k}^{2}$ at $\theta=0$. It is also easy to confirm that $\underline{\tau}_{1}^{C}<\underline{\tau}_{2}^{C}$ for $\theta \in(0,4 \bar{k})$ and $\underline{\tau}_{1}^{C}=\underline{\tau}_{2}^{C}$ at $\theta=0$. As $\theta$ approaches the upper bound (i.e., $4 \bar{k}$ ), the lower bound $\underline{\tau}_{2}^{C}$ goes to plus infinity. This implies that none of countries will participate in the tax harmonization when the affiliates located in different countries are highly asymmetric in technologies. To guarantee the existence of the optimal cooperative tax, we assume that there exist values of $\theta$ such that $\underline{\tau}_{2}^{C}<1$.

Best-deviation tax rate. The best-deviation tax rate $\tau_{i}^{D}$ maximizes oneperiod's tax revenue in country $i$, given that the other country sets $\tau^{C}$. Substituting out $\tau_{j}$ for $\tau^{C}$ in the best reply function of country $i, i \neq j$, in (12) gives

$$
\tau_{i}^{D}:=\frac{1}{32}\left[16 \tau^{C}+\beta\left(\theta-(-1)^{i} 4 \bar{k}\right)^{2}\right], \quad i=1,2 .
$$

Then use (21) to substitute out for $\tau_{i}$ in the expression for $R_{i}$ in (11), given $\tau_{j}=\tau^{C}, i, j=1,2$ but $i \neq j$, to get the best deviation tax revenue:

$$
R_{i}^{D}:=\frac{\left[16 \tau^{C}+\beta\left(\theta-(-1)^{i} 4 \bar{k}\right)^{2}\right]^{2}}{1024 \beta}, \quad i=1,2
$$

It is straightforward to see that $R_{1}^{D}-R_{2}^{D}>0$, so the more productive country (i.e., country 1 ) gets a higher level of one period's tax revenue when deviating from cooperation. Moreover, it is easy to show that $R_{i}^{D}>R_{i}^{C}$, $i=1,2$. Yet, the implication is not that countries always have an incentive to deviate from coordination, since deviating countries will potentially be punished by reverting to the Nash equilibrium (i.e., the punishment phase) which is accompanied by further lower tax revenues. 
Minimum discount factors under grim-trigger strategies. Let us assume that the tax authorities in both countries adopt the grim-trigger strategy in setting their tax rates; that is, country $i$ sets its capital tax at some predetermined level denoted by $\tau^{C}\left(>\tau_{i}^{N}\right)$ at the beginning of the game onwards as long as country $j(j \neq i)$ maintains $\tau^{C}$, in the previous period. If the tax authority of some country deviates from $\tau^{C}$ in, say, period $t$, then cooperation collapses and triggers punishment which results in a Nash equilibrium from period $t+1$ to forever thereafter. Accordingly, the conditions to sustain cooperation are given by

$$
\frac{1}{1-\delta} R_{i}^{C} \geq R_{i}^{D}+\frac{\delta}{1-\delta} R_{i}^{N}, \quad i=1,2
$$

which are equivalent to

$$
\delta_{i} \geq \frac{R_{i}^{D}-R_{i}^{C}}{R_{i}^{D}-R_{i}^{N}}, \quad i=1,2
$$

The minimum values of both countries' discount factors which sustain cooperation are obtained as follows. For country $i$ we use (19) to substitute out for $R_{i}^{C}$, (22) to substitute out for $R_{i}^{D}$ and (14) for $R_{i}^{N}$ on the right-hand side of (24) to get

$$
\begin{aligned}
\hat{\delta}_{i}: & =\frac{R_{i}^{D}-R_{i}^{C}}{R_{i}^{D}-R_{i}^{N}} \\
& =\frac{9\left[\beta\left(\theta-(-1)^{i} 4 \bar{k}\right)^{2}-16 \tau^{C}\right]^{2}}{9\left[16 \tau^{C}+\beta\left(\theta-(-1)^{i} 4 \bar{k}\right)^{2}\right]^{2}-4 \beta^{2}\left[3 \theta^{2}-(-1)^{i} 8 \bar{k} \theta+48 \bar{k}^{2}\right]^{2}}, \quad i=1,2 .
\end{aligned}
$$

The cooperative tax rate $\tau^{C}$ is sustainable as a subgame perfect equilibrium of the repeated game only in situations where the actual (common) discount factor of both countries, $\delta$, is larger than the threshold discount factor defined by

$$
\delta^{*}=\hat{\delta}_{2}=\max \left\{\hat{\delta}_{1}, \hat{\delta}_{2}\right\}
$$

where inspection of (25) reveals that the minimum discount factor of country 2 is always greater than that of country 1 , except at $\theta=0$ or $\beta=0$ where $\hat{\delta}_{1}=\hat{\delta}_{2}$; hence, the sustainability of tax harmonization depends crucially on whether the actual discount factor $\delta$ is greater or less than $\hat{\delta}_{2}$. Note also that 
when $\beta=0, \hat{\delta}_{1}=\hat{\delta}_{2}=1, i=1,2$, which implies that in order to achieve tax coordination, the tax authorities need to implement somewhat of profits shifting regulations.

Comparative statics. We are now ready to analyze the effect of a change in some principle parameters on the likelihood of cooperation to sustain tax harmonization. To see this, we differentiate $\delta^{*}$ with respect to $\theta$ to get (see Appendix A)

$$
\frac{\partial \delta^{*}}{\partial \theta}=\frac{\partial \hat{\delta}_{2}}{\partial \theta}>0
$$

To understand the economic mechanisms underlying (26), we need to know how an increase in the degree of productivity difference affects the one-shot tax revenue of the respective countries at all phases of the repeated game. To this end, we first differentiate $R_{2}^{C}$ in (19) with respect to $\theta$. This gives ${ }^{5}$

$$
\frac{\partial R_{2}^{C}}{\partial \theta}=\tau^{C} \frac{\partial \pi_{2}^{C}}{\partial \theta}=\frac{\tau^{C}}{8}(\theta-4 \bar{k})<0
$$

for $\theta \in[0,4 \bar{k})$, where $R_{2}^{C}:=\tau^{C} \pi_{2}^{C}$ and $\partial \pi_{2}^{C} / \partial \theta \equiv(\theta-4 \bar{k}) / 8<0$. To explain this result notice that an increase in the difference of productivity has opposite effects on the tax revenues of the two countries given by (19). A higher $\theta$ induces the multinational firm to expand (shrink) its production by making more (less) investments in the high- (low-) productivity country. As a result, the high-productivity country 1 enjoys larger profits, while the low-productivity country 2 does lower profits. Under tax harmonization (i.e., the cooperative phase) there is no incentive for the multinational firm to shift profits across countries due to the common tax rate. In other words, an increasing asymmetry in productivities between countries has only a negative effect on the tax base of country 2, and this explains the observation that country 2 ends up collecting less tax revenue compared to that of country 1 in the cooperative phase. This means that cooperation becomes less attractive for the low-productivity country 2 as the extent of country-specific asymmetry is enhanced.

The effect of an increase in $\theta$ on the tax revenue of country 2 in the deviation phase can be decomposed into tax-rate and tax-base effects as

\footnotetext{
${ }^{5}$ Note that $\partial R_{1}^{C} / \partial \theta=\left(\tau^{C} / 8\right)(\theta+4 \bar{k})>0$ for the high-productivity country 1.
} 
follows: ${ }^{6}$

$$
\frac{\partial R_{2}^{D}}{\partial \theta}=\underbrace{\pi_{2}^{D} \frac{\partial \tau_{2}^{D}}{\partial \theta}}_{\text {tax-rate effect (-) }}+\underbrace{\tau_{2}^{D} \frac{\partial \pi_{2}^{D}}{\partial \theta}}_{\text {tax-base effect (-) }}=\frac{\left[16 \tau^{C}+\beta(\theta-4 \bar{k})^{2}\right](\theta-4 \bar{k})}{256}<0,
$$

where $R_{2}^{D}:=\tau_{2}^{D} \pi_{2}^{D}, \partial \tau_{2}^{D} / \partial \theta=(\beta / 16)(\theta-4 \bar{k})<0$ and $\partial \pi_{2}^{D} / \partial \theta=(1 / 16)(\theta-$ $4 \bar{k})<0$. An increase in $\theta$ activates both tax-rate (i.e., $\partial \tau_{2}^{D} / \partial \theta<0$ ) and taxbase effects (i.e., $\left.\partial \pi_{2}^{D} / \partial \theta<0\right)$ in the deviation phase. The tax-rate effect is negative since a higher $\theta$ leads to a decrease in $\tau_{2}^{D}$ from (21) (recall $\theta<4 \bar{k}$ ). The tax-base effect works through two channels; that is, changes in capital demand and the amount of profits shifted. The tax-base effect arising from variations in capital demand is negative since (9) implies that a higher $\theta$ is associated with a lower $A_{2}$, which causes a reduction in the profit of the affiliate located in country 2 and thus in the tax base (i.e., $\pi_{2}^{D}$ ). On the other hand, the amount of profits shifted to country 2 is increased due to a larger tax rate differential $\tau_{2}^{D}-\tau^{C}$. It follows from $\partial \pi_{2}^{D} / \partial \theta<0$ that the first (negative) tax-base effect dominates the second (positive) tax-base effect. Taken together, an increase in the asymmetries between countries makes deviation less profitable for the low-productivity country 2.

The effect of an increase in $\theta$ on country 2's tax revenue in the Nash equilibrium phase can also be decomposed into the tax-rate and tax-base effects: ${ }^{7}$

$$
\frac{\partial R_{2}^{N}}{\partial \theta}=\underbrace{\pi_{2}^{N} \frac{\partial \tau_{2}^{N}}{\partial \theta}}_{\text {tax-rate effect (?) }}+\underbrace{\tau_{2}^{N} \frac{\partial \pi_{2}^{N}}{\partial \theta}}_{\text {tax-base effect (?) }}=\frac{\beta\left[3 \theta^{2}-8 \bar{k} \theta+48 \bar{k}^{2}\right](3 \theta-4 \bar{k})}{576} \gtreqless 0,
$$

where $\partial \tau_{2}^{N} / \partial \theta=(\beta / 24)(3 \theta-4 \bar{k}) \gtreqless 0$ and $\partial \pi_{2}^{N} / \partial \theta=(1 / 24)(3 \theta-4 \bar{k}) \gtreqless 0$. Tax revenue in the Nash equilibrium is increasing in $\theta$ for $3 \theta>4 \bar{k}$ and decreasing in $\theta$ for $3 \theta<4 \bar{k}$ provided $\beta \neq 0$. Although a higher $\theta$ unambiguously decreases the capital demand of country 2 , it may increase or decrease $\tau_{2}^{N}$ (see (13)), so does the tax rate differential $\tau_{1}^{N}-\tau_{2}^{N}$; hence, it is uncertain

\footnotetext{
${ }^{6}$ Note that $\partial R_{1}^{D} / \partial \theta=(1 / 256)\left[16 \tau^{C}+\beta(\theta+4 \bar{k})^{2}\right](\theta+4 \bar{k})>0$ for the highproductivity country 1 .

${ }^{7}$ Note that $\partial R_{1}^{N} / \partial \theta=(\beta / 576)\left[3 \theta^{2}+8 \bar{k} \theta+48 \bar{k}^{2}\right](3 \theta+4 \bar{k})>0$ for the highproductivity country 1 .
} 
whether the amount of profits shifted increases or not. Put together, the overall effect on the tax revenue in the Nash equilibrium depends on a given size of $\theta$.

These observations serve as determining the effect on the minimum discount factor in (25) in response to an increase in asymmetries between countries. To determine whether or not to maintain tax harmonization, the tax authority of each country compares the immediate gain from its unilateral deviation with the opportunity cost when reverting to the Nash equilibrium in all the subsequent periods. To simplify the exposition, suppose that the actual discount factor of country 2 happens to coincide with the minimum discount factor $\hat{\delta}_{2}$ in (24). Rearranging the resulting equality of (24) gives

$$
\frac{\hat{\delta}_{2}}{1-\hat{\delta}_{2}}\left(R_{2}^{C}-R_{2}^{N}\right)=R_{2}^{D}-R_{2}^{C} .
$$

The left-hand-side of (30) represents the discounted future (opportunity) costs from country 2's unilateral deviation, while its right-hand side is the immediate gain from deviating. For ease of exposition, we further decompose the discounted future costs on the left-hand-side of (30) into two components: the discount factor component, $\hat{\delta}_{2} /\left(1-\hat{\delta}_{2}\right)$, and the opportunity cost incurred by country $2, R_{2}^{C}-R_{2}^{N}$. Comparing (27) with (28), and with (29) reveals that the effect on the immediate gain from deviation, $\partial\left(R_{2}^{D}-R_{2}^{C}\right) / \partial \theta$, is positive, while that on the future loss, $\partial\left(R_{2}^{C}-R_{2}^{N}\right) / \partial \theta$, is negative. This clearly enhances the incentive of country 2 to deviate:

$$
\frac{\partial \delta^{*}}{\partial \theta}=\frac{\partial \hat{\delta}_{2}}{\partial \theta}>0
$$

This is a consequence of the fact that the negative tax base effect of increasing $\theta$ on $R_{2}^{C}$ tends to overweigh those on $R_{2}^{N}$ and $R_{2}^{D}$. More specifically, although profit shifting usually mitigates or counteracts the tax-base effect caused by changes in $\theta$, there is no opportunity of profit shifting in the cooperative phase and thus the negative tax-base effect on $R_{2}^{C}$ will be most enhanced compared to those on $R_{2}^{N}$ and $R_{2}^{D}$.

We use the same structure of arguments to discuss the economic consequences of an increase in the marginal compliance $\operatorname{costs} \beta$ on the incentives of 
tax authorities to implement tax harmonization. By differentiating $\delta^{*}$ with respect to $\beta$ we obtain (see Appendix A)

$$
\frac{\partial \delta^{*}}{\partial \beta}=\frac{\partial \hat{\delta}_{2}}{\partial \beta}<0
$$

Similarly, differentiating the corresponding tax revenues with respect to $\beta$ yields

$$
\begin{aligned}
& \frac{\partial R_{2}^{C}}{\partial \beta}=0 \\
& \frac{\partial R_{2}^{D}}{\partial \beta}=\frac{\partial \tau_{2}^{D}}{\partial \beta} \pi_{2}^{D}+\tau_{2}^{D} \frac{\partial \pi_{2}^{D}}{\partial \beta}=\tau_{2}^{D} \frac{\beta(\theta-4 \bar{k})^{2}-16 \tau_{2}^{D}}{16 \beta^{2}}<0 \\
& \frac{\partial R_{2}^{N}}{\partial \beta}=\pi_{2}^{N} \frac{\partial \tau_{2}^{N}}{\partial \beta}=\frac{1}{2304}\left[48 \bar{k}^{2}-8 \bar{k} \theta+3 \theta^{2}\right]^{2}>0
\end{aligned}
$$

An increase in $\beta$ has no effect on the productivities of the two countries so that the change has no effect on firm's real investment decisions; hence, there is no tax-base effect through variations in capital demand. Consequently, there remains the tax-base effect through changes in the amount of profits shifted since the multinational firm only engages in profit shifting activities in response to the tax differentials.

Interestingly, higher levels of compliance costs reduce both the gain and its loss associated with the deviation from cooperation in (30). To see this, compare (32) with (33) and with (34), respectively. This comparison reveals that the immediate gain from deviation is decreasing in $\beta$ (i.e., $\left.\partial\left(R_{2}^{D}-R_{2}^{C}\right) / \partial \beta<0\right)$, so does the future loss, (i.e., $\left.\partial\left(R_{2}^{C}-R_{2}^{N}\right) / \partial \beta<0\right)$. However, we can identify that $\left|\partial\left(R_{2}^{D}-R_{2}^{C}\right) / \partial \beta\right|>\left|\partial\left(R_{2}^{C}-R_{2}^{N}\right) / \partial \beta\right|$. Since there is no opportunity of profit shifting in the cooperative phase, a change in $\beta$ has no effect on $R_{2}^{C}$. Hence, the result that $\left|\partial\left(R_{2}^{D}-R_{2}^{C}\right) / \partial \beta\right|>$ $\left|\partial\left(R_{2}^{C}-R_{2}^{N}\right) / \partial \beta\right|$ amounts to $\left|\partial R_{2}^{D} / \partial \beta\right|>\left|\partial R_{2}^{N} / \partial \beta\right|$. The last inequality can be explained as follows. Since in the deviation phase country 2 sets a lower tax rate compared to the Nash tax rate, the multinational firm tends to shift more of the amount of profits from country 1 to 2 compared to that in the Nash equilibrium. The increase in $\beta$ causes a larger reduction in the marginal gain of the country 2's tax base compared to that in the Nash equilibrium, which discourages the incentive of country 2 to deviate. 
The result may stand in stark contrast to the following naive intuition. An increase in the barriers for profit shifting (i.e., higher $\beta$ ) means that it becomes relatively unattractive for the multinational firm to shift profits across borders. Hence, a lower mobility of profits augments the tax revenues of non-cooperating governments, which in turn weakens their incentives to participate in tax harmonization. However, considering the sustainability of tax coordination, we have to take into the effects on the tax revenues in the other phases such as the deviation and cooperative phases of the repeated game.

Proposition 1 In a repeated tax competition game with grim-trigger strategies

(i) there is a subgame perfect equilibrium in which the coordinated equal tax rates (i.e., the revenue-maximizing tax harmonization) are sustained if both countries are sufficiently patient;

(ii) the less productive country has a stronger incentive to deviate from the revenue-maximizing tax harmonization;

(iii) an increase in the difference in productivities among countries makes the revenue-maximizing tax harmonization more difficult; and

(iv) an increase in the concealment cost of profit shifting makes the revenuemaximizing tax harmonization easier.

\section{Renegotiation}

The trigger strategy postulates that countries can be deterred from short-run opportunities by threats of continued future retaliation. It seems counterintuitive that once punishment is activated, it continues forever, because both are hurt by implementing this punishment, although the equilibrium path is a subgame perfect equilibrium.

We can briefly describe the concept of WRP strategies which support the coordinated tax rate $\tau^{C}$ as a subgame perfect equilibrium when renegotiation is allowed as follows. In each period, each country chooses $\tau^{C}$, provided the other country chooses $\tau^{C}$ in the previous period. If country $i$ alone deviates from the coordinated tax rate $\tau^{C}$ by choosing its best-deviation tax rate $\tau_{i}^{D}$ 
in some period, then country $j$ starts to punish $i$ by choosing $\tau_{j}^{N}$ in the next period onwards. Defector $i$ has two options to react. She can either accept the punishment and choose $\tau^{C}$ for a finite sequence of $m$ periods (repentance phase), or not to give in and continue with defection, thus reverting to the Nash equilibrium (retaliation phase). In the first case defector $i$ resumes cooperation after the punishment has been implemented for finite periods, while in the second case the punishment (non-cooperative choice of taxes) is prolonged.

The sequence of the coordinated tax rate $\tau^{C}$ thus constitutes a WRP strategy in an infinitely repeated game between the two tax authorities if the following four conditions are satisfied (see Farrel and Maskin, 1989, page $335)$ :

$$
\begin{aligned}
\frac{1}{1-\delta} R_{i}^{C} & \geq R_{i}^{D}+\frac{\delta}{1-\delta} R_{i}^{N}, \\
\frac{1-\delta^{m+1}}{1-\delta} R_{i}^{C} & \geq R_{i}^{D}+\delta \frac{1-\delta^{m}}{1-\delta} R_{i}\left(\tau^{C}, \tau_{j}^{D}\right), \\
\frac{\delta^{m}}{1-\delta} R_{i}^{C}+\frac{1-\delta^{m}}{1-\delta} R_{i}\left(\tau^{C}, \tau_{j}^{D}\right) & \geq \frac{1}{1-\delta} R_{i}^{N}, \\
\frac{1-\delta^{m}}{1-\delta} R_{j}^{D}+\frac{\delta^{m}}{1-\delta} R_{j}^{C} & \geq \frac{1}{1-\delta} R_{j}^{C}, \quad i=1,2, i \neq j .
\end{aligned}
$$

Condition (35) means that the payoff from deviation, $R_{i}^{D}$, and anticipated realization of Nash revenues, $R_{i}^{N}$, in the retaliation phase must not exceed payoff under cooperation. Condition (36) requires that defection in one period and cooperation resumed after $m$ punishment (repentance) periods gives a lower payoff, $R_{i}\left(\tau^{C}, \tau_{j}^{D}\right)$, compared to cooperation over $m+1$ periods. Condition (37) requires that tax revenues from being punished over $m$ periods and cooperation resumed after $m$ punishment (repentance) periods must not fall short of that from playing non-cooperatively. Condition (38) ensures that punishment is credible in the sense that the punisher has no incentive to renegotiate on the preassigned punishment. For this the punisher (i.e., country $j$ ) must benefit from implementing the preassigned punishment scenario compared to returning to cooperation without punishment. Since $R_{j}^{D} \geq R_{j}^{C}$ implies (38), this condition is trivially satisfied and thus imposes no additional restriction. Furthermore, since it can easily be verified that conditions 
(36) and (37) together imply (35), we can drop (35) also.

Minimum discount factors under WRP strategies. For analytical convenience, assume that the punishment length is restricted to one period (i.e. $m=1$ ) so that conditions (36) and (37), respectively, further simplify to

$$
\begin{aligned}
(1+\delta) R_{i}^{C} & \geq R_{i}^{D}+\delta R_{i}\left(\tau^{C}, \tau_{j}^{D}\right), \\
(1-\delta) R_{i}\left(\tau^{C}, \tau_{j}^{D}\right)+\delta R_{i}^{C} & \geq R_{i}^{N},
\end{aligned}
$$

where, following Stähler (1998), we call (39) and (40) the 'ex-ante' and the 'ex-post' compliance constraints, respectively. To get the minimum values of the discount factors of both countries associated with the respective compliance constraints we rewrite (39) and (40) as

$$
\begin{aligned}
\delta \geq \hat{\delta}_{i}^{E A}:=\frac{R_{i}^{D}-R_{i}^{C}}{R_{i}^{C}-R_{i}\left(\tau^{C}, \tau_{j}^{D}\right)}, & \\
\delta \geq \hat{\delta}_{i}^{E X}:=\frac{R_{i}^{N}-R_{i}\left(\tau^{C}, \tau_{j}^{D}\right)}{R_{i}^{C}-R_{i}\left(\tau^{C}, \tau_{j}^{D}\right)}, & i=1,2, i \neq j,
\end{aligned}
$$

where $R_{i}^{D}$ is given by (22) and $R_{i}^{C}$ is given by (19).

The tax revenue when being punished $R_{i}\left(\tau^{C}, \tau_{j}^{D}\right)$ in the repentance phase is obtained as follows; setting $\tau_{i}$ equal to $\tau^{C}$ and using (21) to substitute out $\tau_{j}$ for $\tau_{j}^{D}$ in the expression for $R_{i}\left(\tau^{C}, \tau_{j}^{D}\right)$ in (11) gives

$$
R_{i}\left(\tau^{C}, \tau_{j}^{D}\right)=\frac{\tau^{C}\left[\beta\left(3 \theta^{2}-(-1)^{i} 8 \bar{k} \theta+48 \bar{k}^{2}\right)-16 \tau^{C}\right]}{32 \beta} .
$$

Since $R_{i}^{N}<R_{i}\left(\tau^{C}, \tau_{j}^{D}\right)$ would economically mean that repentance becomes meaningless, we solve the inequality of $R_{i}^{N} \geq R_{i}\left(\tau^{C}, \tau_{j}^{D}\right)$ for the lower bound of the harmonized tax rate, $\underline{\underline{\tau}}_{i}^{C}$ :

$$
\underline{\underline{\tau}}_{i}^{C}=\frac{1}{24} \beta\left[3 \theta^{2}-(-1)^{i} 8 \bar{k} \theta+48 \bar{k}^{2}\right] \geq 0, \quad i=1,2
$$

implying, from (20), that $\underline{\tau}_{i}^{C}>\underline{\tau}_{i}^{C}$. In what follows, we assume that $\underline{\tau}_{i}^{C}<1$.

To yield a characterization of the minimum discount factors in the 'exante' and 'ex-post' compliance constraints for the two countries, rewrite (41) and (42) using $R_{i}^{D}$ from (22), $R_{i}^{C}$ from (19) and $R_{i}\left(\tau^{C}, \tau_{j}^{D}\right)$ from (43): For 
$i=1,2$,

$\begin{aligned} \hat{\delta}_{i}^{E A} & =\frac{\left[\beta\left(\theta-(-1)^{i} 4 \bar{k}\right)^{2}-16 \tau^{C}\right]^{2}}{32 \tau^{C}\left[16 \tau^{C}-\beta\left(\theta+(-1)^{i} 4 \bar{k}\right)^{2}\right]}, \\ \hat{\delta}_{i}^{E X} & =\frac{\left[24 \tau^{C}-\beta\left(3 \theta^{2}-8(-1)^{i} \bar{k} \theta+48 \bar{k}^{2}\right)\right]\left[48 \tau^{C}-\beta\left(3 \theta^{2}-8(-1)^{i} \bar{k} \theta+48 \bar{k}^{2}\right)\right]}{72 \tau^{C}\left[16 \tau^{C}-\beta\left(\theta+4(-1)^{i} \bar{k}\right)^{2}\right]} .\end{aligned}$

Minimum discount factor. If the actual (common) discount factors for both countries exceed the minimum values for both compliance constraints, given $\tau^{C}$, the two countries find it in their interests to cooperate. Let $\delta^{* *}:=$ $\max \left\{\hat{\delta}_{1}^{E A}, \hat{\delta}_{2}^{E A}, \hat{\delta}_{1}^{E X}, \hat{\delta}_{2}^{E X}\right\}$. Inspection of (46) shows that $\hat{\delta}_{2}^{E X}>\hat{\delta}_{1}^{E X}$, and (45) implies that $\hat{\delta}_{2}^{E A}>\hat{\delta}_{1}^{E A}$, except at $\beta=0$ or $\theta=0$ where $\hat{\delta}_{2}^{E X}=\hat{\delta}_{1}^{E X}$ and $\hat{\delta}_{2}^{E A}=\hat{\delta}_{1}^{E A}$. Then

$$
\delta^{* *}\left(\tau^{C}\right) \begin{cases}=\hat{\delta}_{2}^{E A} & \text { if } \tau^{C} \in\left[\underline{\underline{\tau}}^{C}, \widetilde{\tau}^{C}\right], \\ =\hat{\delta}_{2}^{E X} & \text { if } \tau^{C} \in\left[\widetilde{\tau}^{C}, 1\right],\end{cases}
$$

whose graphs are depicted in Figs.1-3 (see Appendix C also). Note also that the threshold discount factor for the ex-ante compliance constraint associated with WRP strategies is higher than that under grim-trigger strategies:

$$
\begin{aligned}
& \hat{\delta}_{2}-\hat{\delta}_{2}^{E A}=64 \beta \tau^{C}\left(80 \bar{k}^{2}+5 \theta^{2}-32 \theta \bar{k}\right)+1792 \tau^{C^{2}} \\
& -\beta^{2}\left(8 \theta \bar{k}+48 \bar{k}^{2}+3 \theta^{2}\right)\left(144 \bar{k}^{2}+9 \theta^{2}-40 \theta \bar{k}\right)>0 .
\end{aligned}
$$

Since it is seen from Figs. 1-3 that $\hat{\delta}_{2}^{E X}$ is always higher than that under grim-trigger strategies for its relevant range of $\tau^{C}$, it is concluded that tax harmonization under WRP strategies become more difficult compared to that under WRP strategies. This is mainly due to shorter punishment periods under WRP strategies (see also Stähler, 1998).

As before, we investigate the effects of a change in the principle model parameters $\theta$ and $\beta$ on the likelihood to implement tax coordination. To interpret results in a way outlined in the previous section, we rewrite con- 
straints (41) and (42), respectively, as

$$
\begin{aligned}
R_{2}^{D}-R_{2}^{C} & =\hat{\delta}_{2}^{E A}\left[R_{2}^{C}-R_{2}\left(\tau^{C}, \tau_{1}^{D}\right)\right], \\
R_{2}^{N}-R_{2}\left(\tau^{C}, \tau_{j}^{D}\right) & =\hat{\delta}_{2}^{E X}\left[R_{2}^{C}-R_{2}\left(\tau^{C}, \tau_{1}^{D}\right)\right],
\end{aligned}
$$

whose left-hand sides represent the immediate gains to deviate from the preassigned scenarios, and whose right-hand sides represent the discounted (one-period) opportunity costs from deviation.

Let us first discuss the economic consequences of an increase in the asymmetry measured by $\theta$. Condition (47) associated with the ex-ante compliance is very similar to condition (30) associated with grim-trigger strategies, except that $R_{2}^{N}$ is replaced by $R_{2}\left(\tau^{C}, \tau_{1}^{D}\right)$; hence, $\partial\left(R_{2}^{D}-R_{2}^{C}\right) / \partial \theta>0$ as before, while $\partial\left(R_{2}^{C}-R_{2}\left(\tau^{C}, \tau_{1}^{D}\right)\right) / \partial \theta<0$, whose sign follows from (27) and (49). Although differentiating (43) yields ${ }^{8}$

$$
\frac{\partial R_{2}\left(\tau^{C}, \tau_{1}^{D}\right)}{\partial \theta}=\frac{\tau^{C}(6 \theta-8 \bar{k})}{16} \gtreqless 0,
$$

the unambiguous negative sign of $\partial\left(R_{2}^{C}-R_{2}\left(\tau^{C}, \tau_{1}^{D}\right)\right) / \partial \theta$ follows from the fact that the negative sign of $\partial R_{2}^{C} / \partial \theta$ dominates. The reason is the same as before, that is, the reduction in $R_{2}^{C}$ is most enhanced due to the absence of profit shifting opportunities, while the negative tax-base effect caused by increasing $\theta$ on $R_{2}\left(\tau^{C}, \tau_{1}^{D}\right)$ is partially canceled out by the counteracting profit shifting effect. Put together, since the cost from deviation is decreased while the gain is increased, the incentive of country 2 to deviate from the ex-ante compliance constraint is strengthened.

In the ex-post compliance constraint (48), the (opportunity) cost associated with refusing repentance unambiguously becomes smaller for the same reason stated above (i.e., $\left.\partial\left(R_{2}^{C}-R_{2}\left(\tau^{C}, \tau_{1}^{D}\right)\right) / \partial \theta<0\right)$, while $\partial\left(R_{2}^{N}-\right.$ $\left.R_{2}\left(\tau^{C}, \tau_{1}^{D}\right)\right) / \partial \theta \gtreqless 0$, which follows from (29) and (49). Nevertheless, we can confirm that the reduction in the cost of refusing repentance in absolute value overweighs the reduction in the gain by differentiating (45) and (46)

\footnotetext{
${ }^{8}$ The ambiguity of (49) stems from the fact that although the tax base (i.e., $\left.\pi_{2}\right)$ is shrunk in response to a decrease in $A_{2}$, the amount of profits shifted from country 2 to 1 in the repentance phase is also decreased by the increase in $\tau_{1}^{D}$ resulting from higher $A_{1}$.
} 


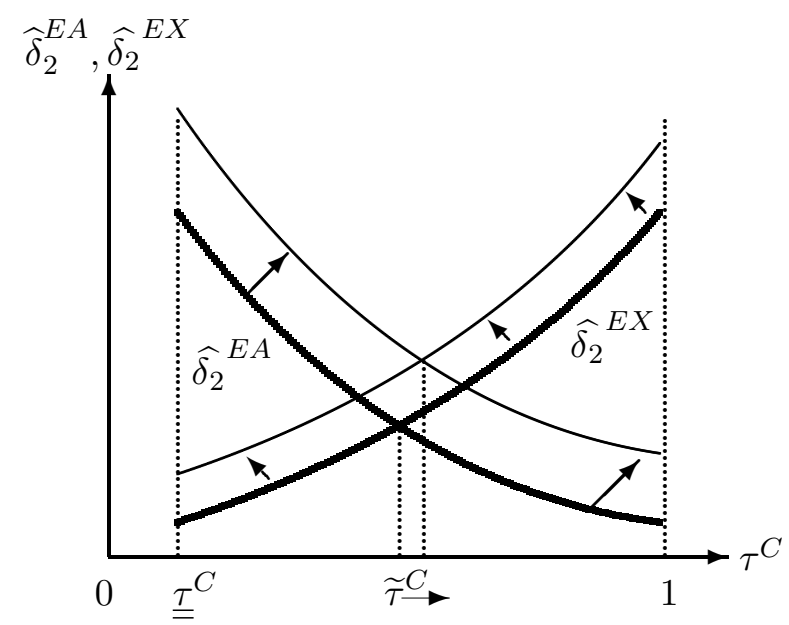

Figure 1: An increase in $\theta$ shifts the ${\widehat{\delta_{2}}}^{E A}$ and the ${\widehat{\delta_{2}}}^{E X}$-curve up; note that $\partial \widetilde{\tau}^{C} / \partial \theta>0$ from (C.1).

with respect to $\theta$ (see Appendix B):

$$
\frac{\partial \hat{\delta}_{2}^{E A}}{\partial \theta}>0 \text { and } \frac{\partial \hat{\delta}_{2}^{E X}}{\partial \theta}>0 .
$$

The reason for the unambiguous effect on $\hat{\delta}_{2}^{E X}$ is the same as before; that is, the reduction of $R_{2}^{C}$ in response to a higher $\theta$ has a dominant impact compared to those on $R_{2}^{N}$ and $R_{2}\left(\tau^{C}, \tau_{1}^{D}\right)$. As a result, as illustrated in Fig. 1, over the appropriate range of the coordinated tax rate $\tau^{C}$ which is less than one and is consistent with (44), the $\hat{\delta}_{2}^{E A}$ and $\hat{\delta}_{2}^{E X}$ curves both shift upward in response to the increase in $\theta$; hence, it is harder to sustain tax coordination at any level of $\tau^{C}$. Since this result is essentially the same as that under grim-trigger strategies, increased asymmetry between two countries tends to harm tax harmonization irrespective of whether renegotiation is possible or not.

In the previous section we obtained the result that an increase in the concealment costs parameter $\beta$ unambiguously increases the likelihood to sustain cooperation as an equilibrium outcome. This is not the case here. It follows from the result of grim-trigger strategies that $\partial\left(R_{2}^{D}-R_{2}^{C}\right) / \partial \beta<0$, while straightforward differentiation yields $\partial\left(R_{2}^{C}-R_{2}\left(\tau^{C}, \tau_{1}^{D}\right)\right) / \partial \beta<0 . R_{2}^{C}$ is unaffected by changes in $\beta$ due to the absence of profit shifting opportunities, while a higher $\beta$ unambiguously increases $R_{2}\left(\tau^{C}, \tau_{1}^{D}\right)$ thereby reducing the cost of being punished in the repentance phase. This is because the in- 
crease in $\beta$ deters a outflow of profit from country 2 to 1 in the repentance phase, which ends up higher profits and thus the increased tax base of country 2. Since the cost and gain associated with the deviation from repentance both fall, the ultimate impact on $\hat{\delta}_{2}^{E A}$ depends on the relative size of those reductions. Differentiation of (45) yields (see Appendix B)

$$
\frac{\partial \hat{\delta}_{2}^{E A}}{\partial \beta}>0,
$$

which implies that the reduction in the cost of deviation in absolute value outweighs that in its gain. This stems from the difference in tax rates associated with $R_{2}^{D}$ and $R_{2}\left(\tau^{C}, \tau_{1}^{D}\right)$ (i.e., $\left.\tau_{2}^{D}<\tau^{C}\right)$; consequently, the marginal impact of an increase in $\beta$ on $R_{2}\left(\tau^{C}, \tau_{1}^{D}\right)$ dominates that on $R_{2}^{D}$.

As to the ex-post compliance constraint (48), straightforward differentiation yields $\partial\left(R_{2}^{N}-R_{2}\left(\tau^{C}, \tau_{1}^{D}\right)\right) / \partial \beta<0$, although $R_{2}\left(\tau^{C}, \tau_{1}^{D}\right)$ and $R_{2}^{N}$ both increase. This unambiguous sign stems from the difference in the marginal impacts of an increase in $\beta$ on $R_{2}\left(\tau^{C}, \tau_{1}^{D}\right)$ and $R_{2}^{N}$, which are determined by the tax rate differences, i.e., $\left|\tau_{1}^{N}-\tau_{2}^{N}\right|<\left|\tau_{1}^{D}-\tau^{C}\right|$. Since $\partial\left(R_{2}^{C}-R_{2}\left(\tau^{C}, \tau_{1}^{D}\right)\right) / \partial \beta<0$, the cost and the gain from refusing repentance both fall. However, straightforward differentiation of (48) yields

$$
\frac{\partial \hat{\delta}_{2}^{E X}}{\partial \beta}<0
$$

which implies that the reduction in the gain from refusing repentance overweighs the cost reduction in absolute value (i.e., $\left|\partial\left(R_{2}^{N}-R_{2}\left(\tau^{C}, \tau_{1}^{D}\right)\right) / \partial \beta\right|>$ $\left.\left|\partial\left(R_{2}^{C}-R_{2}\left(\tau^{C}, \tau_{1}^{D}\right)\right) / \partial \beta\right|\right)$, thus making the punished country easier to accept repentance. This is because $R_{2}^{N}$ increases (see (13)), while $R_{2}^{C}$ remains unchanged in response to the increase in $\beta$. Hence, as before, the changes of the government tax revenue rely critically on whether there exist the opportunities of profit-shifting or not. Notably, as illustrated in Fig. 2, over the appropriate range of the coordinated tax rate $\tau^{C}$ the $\hat{\delta}_{2}^{E A}$ curve shifts upward, while the $\hat{\delta}_{2}^{E X}$ curves shifts downward, so that the minimum discount factor becomes larger for lower values of $\tau^{C}$, whereas it becomes smaller for higher values of $\tau^{C}$.

Proposition 2 In a repeated tax competition game with weakly 


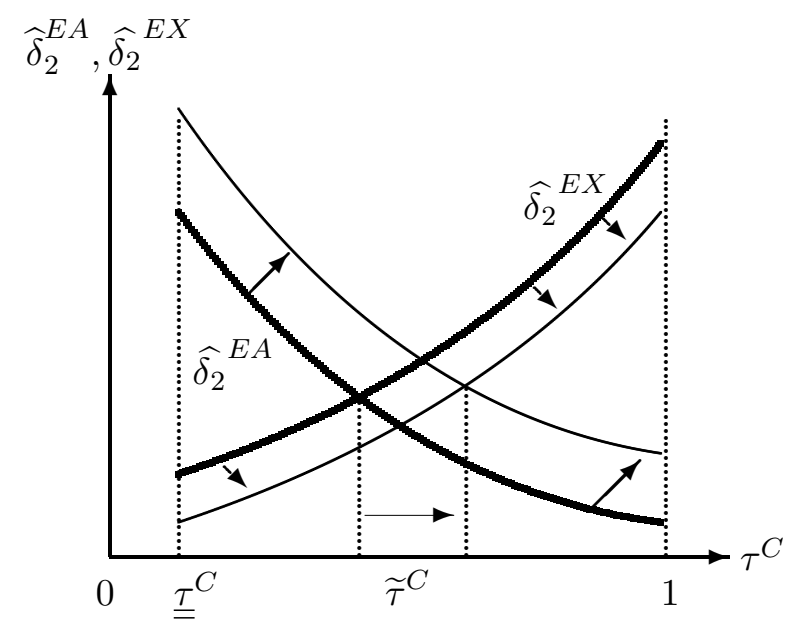

Figure 2: An increase in $\beta$ shifts the ${\widehat{\delta_{2}}}^{E A}$-curve up and the ${\widehat{\delta_{2}}}^{E X}$-curve down; note that $\partial \widetilde{\tau}^{C} / \partial \beta>0$ from (C.1).

renegotiation-proof strategies

(i) there is a subgame perfect equilibrium in which the cooperative equal tax rates (i.e., the revenue-maximizing tax harmonization) are sustained if both countries have sufficiently high discount factors;

(ii) an increase in the difference of productivities among countries makes the revenue-maximizing tax harmonization more difficult; and

(iii) an increase in the concealment cost of profit shifting makes the revenuemaximizing tax harmonization easier if the coordinated tax rate is higher than $\tilde{\tau}^{C}$, vice versa if the coordinated tax rate is lower than $\tilde{\tau}^{C}$.

It might be surprising at first sight that an increase in concealment costs may not increase the chances for implementing tax harmonization. Rather, it would be untrue except when the cooperative tax rate is set at relatively higher levels. The investment in repentance becomes relatively expensive for a deviating (a punished) country, because the deviating country has to charge a relatively higher tax rate compared to the free-riding tax rate by the punisher to implement repentance, and thus a deviating country must incur by a greater loss on its tax revenue. Higher $\beta$ reduces this loss by deterring an outflow of profits (=the tax base), which makes the deviator easier to accept repentance. In other words, the opportunities of profit shifting make the responses of the tax base to changes in tax rates less sensitive, thereby mitigating the loss of the tax base for a deviating country. 


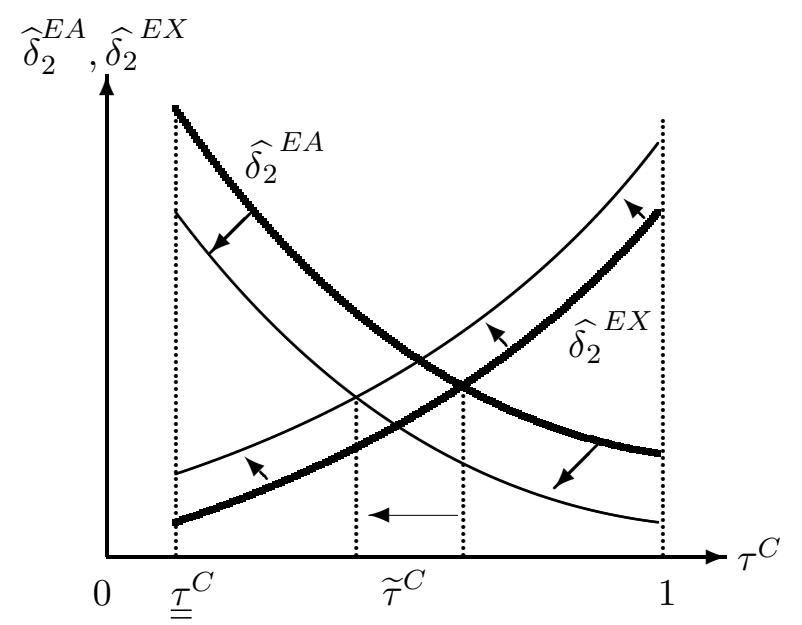

Figure 3: An increase in the period of punishment, $m$, shifts the $\hat{\delta}_{2}^{E A}$ and the $\hat{\delta}_{2}^{E X}$-curve down and up, respectively.

\section{Extensions}

In this section we will consider four extensions of the basic model. ${ }^{9}$ Due to space restrictions, we can only outline the respective extensions. The first extension is to allow punishment for not only one but $m>1$ periods. To do this, rewrite (36) and (37) as follows:

$$
\begin{aligned}
\left(1+\delta+\ldots+\delta^{m}\right) R_{i}^{C} & \geq R_{i}^{D}+\left(\delta+\delta^{2}+\ldots+\delta^{m}\right) R_{i}\left(\tau^{C}, \tau_{j}^{D}\right), \\
\delta^{m} R_{i}^{C}+\left(1-\delta^{m}\right) R_{i}\left(\tau^{C}, \tau_{j}^{D}\right) & \geq R_{i}^{N}, \quad i=1,2, i \neq j .
\end{aligned}
$$

An increase in $m$ causes a higher value of left-hand side of (52) and reduces the right-hand side of (53) for $R_{i}^{C} \geq R_{i}\left(\tau^{C}, \tau_{j}^{D}\right)$. As a consequence the incentive of deviation from cooperation is weakened by the increase in $m$. Fig. 3 depicts the change of the minimum discount factors associated with the ex-ante and ex-post compliance constraints in response to increasing $m$. Although one may expect that the effectiveness of punishment will be enhanced with $m$, thus making cooperation easier, this conjecture may not be true. Inspection of Fig. 3 reveals that the incentive for deviation from cooperation is strengthened for a higher cooperative tax (larger than $\tilde{\tau}^{C}$ ) is chosen, whereas the presence of a lower cooperative tax (smaller than $\tilde{\tau}^{C}$ ) increases the possibility to implement tax harmonization.

\footnotetext{
${ }^{9}$ All extensions made in this section have been suggested by two anonymous referees of this journal. We highly appreciate their constructive suggestions.
} 
It is straightforward to extend the two-country model to a $n$-country model. ${ }^{10}$ Without loss of generality, we focus on a three-country model where the productivity of each country is ranked according to $A_{1}>A_{2}>A_{3}$. Then tax authorities set $\tau_{1}^{N}>\tau_{2}^{N}>\tau_{3}^{N}$. Under this ranking, the multinational firm makes profit shifting to the lowest-productivity country 3 . Let us concentrate on grim trigger strategies. Straight-armed calculation gives the threshold discount factor:

$$
\delta^{*}(3)=\hat{\delta}_{3}=\max \left\{\hat{\delta}_{1}, \hat{\delta}_{2}, \hat{\delta}_{3}\right\}
$$

where $\delta^{*}(3)$ represents the threshold discount factor for a three-country case. ${ }^{11}$ Direct comparison reveals that tax harmonization becomes less likely in the three-county case:

$$
\delta^{*}(3)>\delta^{*}(2)
$$

where $\delta^{*}(2)\left(=\hat{\delta}_{2}\right.$ in $\left.(25)\right)$ represents the threshold discount factor for the two-country case. It is concluded that adding a third country reduces the sustainability of tax harmonization. This is because as increasing the number of competing countries augments the degree of productivity difference across countries, the incentive of deviation for the lowest productivity country is enhanced (which is also consistent with (26)), thereby making full tax coordination less likely.

A more interesting extension is to consider partial tax coordination in which in the economy composed of $n$ countries only the subset of countries, say $k(k<n)$, forms the tax union to implement tax harmonization. However, even in a three-country model we have to examine three combinations of partial tax coordination. Due to space restrictions, we do not conduct a full analysis in the present paper. Instead, we will give some intuitive argument based on Itaya et al. (2010). They have considered the sustainability of partial tax harmonization in the repeated interaction tax competition model among symmetric countries where there are neither multinational firms nor profit shifting. Their paper shows that since an increase in the total number of countries $n$ (given a fixed number of $k$ ) intensifies tax competition, partial tax coordination among $k$ countries becomes more sustainable. Conversely,

\footnotetext{
${ }^{10}$ Calculations for the three-country-case can be obtained from the authors upon request.

${ }^{11}$ Detailed results are available from the corresponding author upon request.
} 
since an increase in $k$ (given a fixed number of $n$ ) reduces the number of players thereby mitigating the pressure of tax competition, which increases $R_{i}^{N}$ (i.e., the punishment becomes weaker), and thus making partial tax coordination less sustainable. The main driving force for these results is the intensity of tax competition. We expect that the same logic will work in our tax competition model with multinational profit shifting.

In practice, the concealment costs of multinational profit shifting activities are largely determined by the tax authorities' resources and efforts assigned to control tax evasion activities. Against this background, it would be more reasonable for the tax authorities to regard the corporate concealment cost as a strategic choice variable, and thus we briefly consider a model in which the tax authorities can choose both the tax rate as well as attempting to control profit shifting (see, e.g., Peralta et al., 2006). We assume that the tax authorities' resources and efforts assigned to profit shifting control can be captured by the size of $\beta$ in the profit-shifting cost function (2). The one-shot tax revenue function (11) becomes

$$
\hat{R}_{i}:=\tau_{i}\left[\frac{\left(\theta-(-1)^{i} 4 \bar{k}\right)^{2}}{16}+(-1)^{i} \frac{\tau_{1}-\tau_{2}}{\beta_{i}}\right]-\frac{\gamma}{2} \beta_{i}^{2}, \quad i=1,2
$$

where $\beta_{i}$ is a choice variable for the tax authority of country $i$, and the $(\gamma / 2) \beta_{i}^{2}$ represents a convex cost function. In the Nash equilibrium

$$
\beta_{i}^{N}=\left[(-1)^{i} \frac{\tau_{i}\left(\tau_{2}-\tau_{1}\right)}{\gamma}\right]^{\frac{1}{3}}, \quad i=1,2
$$

Since the high-productivity country 1 levies a higher tax (i.e., $\tau_{1}>\tau_{2}$ ), the choice of $\beta_{i}$ for country 2 tends to set the lowest feasible value, i.e., $\beta_{i}=0$. Country 2 enjoys an inflow of profits and there is no incentive to deter this profit inflow by engaging costly profit shifting regulations. This also accord with the casual observation that 'tax haven' countries adopt simple procedures to fight against profit shifting. Moreover, it follows from (22) that $\hat{R}_{i}^{D} \rightarrow \infty$ as $\beta_{i} \rightarrow 0$. This implies that the tax heaven (low-productivity) country always has no incentive to participate in tax harmonization.

Finally, we consider the repeated interaction tax competition between countries of different size instead of productivity difference. Denoting by $s_{i}$ 
the exogenous share of country $i$ in the world' population such that $s_{1}+s_{2}=$ 1, the market equilibrium condition of the capital market becomes:

$$
s_{1} k_{1}(r)+s_{2} k_{2}(r)=\bar{k}
$$

In a related paper Stöwhase (2005) focuses on symmetric production technologies, i.e., $\theta=0$, and analyzes the effects of strategic choice of property taxes when countries differ in population size $s_{1}>s_{2}$. In his static model, Stöwhase shows that the small country has some extra gains in the Nash equilibrium, which makes tax harmonization more difficult compared to the model with no size difference. This conclusion does not hold true in our model where governments choose taxes on profits repeatedly. Indeed,

$$
\frac{\partial \delta^{*}}{\partial s_{1}}=\frac{\partial \hat{\delta}_{2}}{\partial s_{1}}=0
$$

which immediately follows from the fact that the tax base of each country is not affected by changes in the distribution of population since the demand functions for capital (4) and the interest rate (8) are not a function of the population distribution.

\section{Conclusion}

A number of recent papers (e.g., Devereux et al., 2008; Huizinga and Laeven, 2008) stress that (i) corporate tax rates differ between countries, (ii) tax competition does occur within the EU and elsewhere and (iii) international profit shifting leads to a substantial redistribution of national corporate tax revenues. Based on those observations, any extensive cooperative agreements or tacit coordination has not materialized yet and are unlikely to be materialized in the near future. Interpreting these facts in the light of our theoretical results, it would be tempted to conclude that the discount factors of realworld governments are sufficiently low. This conclusion could arise from the political economic reasons in that short-sighted governments (or bureaucrats) may stem from the voting behavior of citizens. The governments tend to seek for a good performance in the short run, because their fear of the possibility that they may lose their office in the next election derives them to seek for 
short-run better performances. Griffith et al. (2008) raise further reasons; first, national governments are jealously guarding their fiscal sovereignty; second, the potential welfare gain from international tax coordination are likely to be rather small and unevenly distributed across countries. In reality, the unevenly distributed potential welfare gains attribute to a variety of heterogeneity among countries in terms of the productivity difference, population size, the existing national tax system, the degree of economic development, history, living standard, political situations, and so on. Hence, tax harmonization creates losers as well as winners. In particular, as shown in Section 5 of this paper, the 'tax heaven' country strongly opposes against establishing consolidated measure of tax harmonization.

Our paper points out that renegotiation causes a remarkable difference in the effects of a variation in the costs of profit shifting on the possibility to establish tax harmonization as an equilibrium of the repeated interaction tax competition game. In the real world renegotiation is likely to generate transaction costs, and since contracts are usually incomplete ones in reality, renegotiation in actual economies would realistically generate even higher costs as that strategic costs caused in WRP strategies. Our result indicates that eliminating or reducing such costly renegotiations serves in the successful introduction of standardization or consolidated tax bases (such as switch from Separating Accounting which is currently employed most European countries to a system of a Formula Apportionment).

The present analysis also suggests that the outcome also depends on the precise level of the envisaged harmonized tax rate when renegotiation is allowed. This may also play a key role in the successful introduction of the consolidation of tax harmonization in the European Union. Nevertheless, much more econometric and theoretical work is needed to gain more knowledge about the dynamics in international treaty (re)negotiations.

The model used in this paper certainly is highly stylized and rests on some strongly simplifying assumptions. As stated in Section 5, we need to further explore the sustainability of partial tax harmonization among asymmetric countries. Another rather obvious model extension would be to introduce welfare maximizing governments, although tractability would certainly dictate the use of numerical methods to solve for outcomes with asymmetric 
countries. Thirdly, although we have investigated a model framework of Peralta et al. (2006) with repeated government interactions in which governments choose both the tax rate as well as the degree of profit shifting control, it would be interesting to extend it to a setting where tax authorities' control intensity is non-observable (a hidden action) for the governments of the other countries. To analyze this issue, we need to employ repeated games with imperfect monitoring.

\section{A Appendix}

Differentiating (25) with respect to $\theta$ yields

$$
\begin{aligned}
\frac{\partial \delta^{*}}{\partial \theta} & =-\frac{9\left[-16 \tau^{C}+\beta(-4 \bar{k}+\theta)^{2}\right]^{2}\left[-8 \beta^{2}(-8 \bar{k}+6 \theta)\left(48 \bar{k}^{2}-8 \bar{k} \theta+3 \theta^{2}\right)^{2}\right.}{\left[-4 \beta^{2}\left(48 \bar{k}^{2}-8 \theta+3 \theta^{2}\right)^{2}+9\left(16 \tau^{C}+\beta(-4 \bar{k}+\theta)^{2}\right)^{2}\right]^{2}} \\
& +\frac{36 \beta(-4 \bar{k}+\theta)\left[-16 \tau^{C}+\beta(-4 \bar{k}+\theta)^{2}\right]}{-4 \beta^{2}\left(48 \bar{k}^{2}-8 \bar{k} \theta+3 \theta^{2}\right)^{2}+9\left(16 \tau^{C}+\beta(-4 \bar{k}+\theta)^{2}\right)^{2}} .
\end{aligned}
$$

Taking a common denominator of (A.1) and then ignoring the denominator and the common factor $36\left[-16 \tau^{C}+\beta(-4 \bar{k}+\theta)^{2}\right]$ of the resultant expression yields

$$
\begin{aligned}
& -\left[-16 \tau^{C}+\beta(-4 \bar{k}+\theta)^{2}\right]\left[-4 \beta^{2}(-4 \bar{k}+3 \theta)\left(48 \bar{k}^{2}-8 \bar{k} \theta+3 \theta^{2}\right)+\right. \\
& \left.9 \beta(-4 \bar{k}+\theta)\left(16 \tau^{C}+\beta(-4 \bar{k}+\theta)^{2}\right)\right]+\beta(-4 \bar{k}+\theta) S
\end{aligned}
$$

where $S:=-4 \beta^{2}\left(48 \bar{k}^{2}-8 \bar{k} \theta+3 \theta^{2}\right)^{2}+9\left[16 \tau^{C}+\beta(-4 \bar{k}+\theta)^{2}\right]^{2}$. Rearranging and collecting terms,

$$
\begin{aligned}
= & {\left[S-9\left(16 \tau^{C}-\beta(-4 \bar{k}+\theta)^{2}\right)\left(16 \tau^{C}+\beta(-4 \bar{k}+\theta)^{2}\right)\right] \frac{16 \tau^{C}}{-4 \bar{k}+\theta} } \\
& -\left[16 \tau^{C}-\beta(-4 \bar{k}+\theta)^{2}\right]\left[32 \beta^{2} \bar{k}\left(48 \bar{k}^{2}-8 \bar{k} \theta+3 \theta^{2}\right)\right] .
\end{aligned}
$$

By definition $\hat{\delta}<1$ in (25), implying that the first component of the first term in (A.2) is negative, and, moreover, its second term of (A.2) is clearly 
negative. Taking into account $-16 \tau^{C}+\beta(-4 \bar{k}+\theta)^{2}<0$, we have $(26)$.

On the other hand, differentiating (25) with respect to $\theta$ yields

$$
\begin{gathered}
\frac{\partial \delta^{*}}{\partial \beta}=-\frac{9\left[-16 \tau^{C}+\beta(-4 \bar{k}+\theta)^{2}\right]^{2}\left[-8 \beta\left(48 \bar{k}^{2}-8 \bar{k} \theta+3 \theta^{2}\right)^{2}\right.}{\left[-4 \beta^{2}\left(48 \bar{k}^{2}-8 \bar{k} \theta+3 \theta^{2}\right)^{2}+9\left(16 \tau^{C}+\beta(-4 \bar{k}+\theta)^{2}\right)^{2}\right]^{2}} \\
+\frac{18(-4 \bar{k}+\theta)^{2}\left[-16 \tau^{C}+\beta(-4 \bar{k}+\theta)^{2}\right]}{-4 \beta^{2}\left(48 \bar{k}^{2}-8 \bar{k} \theta+3 \theta^{2}\right)^{2}+9\left(16 \tau^{C}+\beta(-4 \bar{k}+\theta)^{2}\right)^{2}} .
\end{gathered}
$$

After ignoring a common denominator of (A.3), we further ignore the common factors $18\left[-16 \tau^{C}+\beta(-4 \bar{k}+\theta)^{2}\right]$ and $16 \tau^{C} / \beta$ of the resultant expression and rearrange to get

$$
\begin{gathered}
{\left[-4 \beta^{2}\left(48 \bar{k}^{2}-8 \bar{k} \theta+3 \theta^{2}\right)^{2}+9\left(16 \tau^{C}+\beta(-4 \bar{k}+\theta)^{2}\right)^{2}\right]} \\
-9\left[16 \tau^{C}-\beta(-4 \bar{k}+\theta)^{2}\right]\left[16 \tau^{C}+\beta(-4 \bar{k}+\theta)^{2}\right] \\
\geq\left[-4 \beta^{2}\left(48 \bar{k}^{2}-8 \bar{k} \theta+3 \theta^{2}\right)^{2}+9\left(16 \tau^{C}+\beta(-4 \bar{k}+\theta)^{2}\right)^{2}\right] \\
-9\left[16 \tau^{C}+\beta(-4 \bar{k}+\theta)^{2}\right]^{2}>0 .
\end{gathered}
$$

The last inequality follows from the fact that $1>\hat{\delta}$ in (25), which proves (31).

\section{B Appendix}

The effect of a change in $\theta$ in the ex-ante compliance constraint of a WRP equilibrium can be obtained by differentiating (45) with respect to $\theta$ :

$\frac{\partial \hat{\delta}_{2}^{E A}}{\partial \theta}=\frac{\beta(4 \bar{k}+\theta)\left[-16 \tau^{C}+\beta(-4 \bar{k}+\theta)^{2}\right]^{2}}{16 \tau^{C}\left[16 \tau^{C}-\beta(4 \bar{k}+\theta)^{2}\right]^{2}}+\frac{\beta(-4 \bar{k}+\theta)\left[-16 \tau^{C}+\beta(-4 \bar{k}+\theta)^{2}\right]}{8 \tau^{C}\left[16 \tau^{C}-\beta(4 \bar{k}+\theta)^{2}\right]}>0$

whose positive sign immediately follows from $-4 \bar{k}+\theta<0$ and the participation constrain $\tau^{C}>\underline{\underline{\tau}}^{C}>1 / 16 \beta(4 \bar{k}+\theta)^{2}$. 
In order to identify the effect of a change in $\theta$ in the the ex-post compliance constraint, we differentiate (46) with respect to $\theta$ to get

$$
\begin{gathered}
\frac{\partial \hat{\delta}_{2}^{E X}}{\partial \theta}=-\frac{\beta(8 \bar{k}-6 \theta)\left[24 \tau^{C}+\beta\left(-48 \bar{k}^{2}+8 \bar{k} \theta-3 \theta^{2}\right)\right]}{72 \tau^{C}\left[-16 \tau^{C}+\beta(4 \bar{k}+\theta)^{2}\right]} \\
-\frac{\beta(8 \bar{k}-6 \theta)\left[48 \tau^{C}+\beta\left(-48 \bar{k}^{2}+8 \bar{k} \theta-3 \theta^{2}\right)\right]}{72 \tau^{C}\left[-16 \tau^{C}+\beta(4 \bar{k}+\theta)^{2}\right]} \\
+\frac{2 \beta(4 \bar{k}+\theta)\left[24 \tau^{C}+\beta\left(-48 \bar{k}^{2}+8 \bar{k} \theta-3 \theta^{2}\right)\right]\left[48 \tau^{C}+\beta\left(-48 \bar{k}^{2}+8 \bar{k} \theta-3 \theta^{2}\right)\right]}{72 \tau^{C}\left[-16 \tau^{C}+\beta(4 \bar{k}+\theta)^{2}\right]^{2}}
\end{gathered}
$$

Ignoring the denominator of (B.1) and dividing the resultant expression by $2 \beta$ yields

$$
\begin{aligned}
& =-4 \theta\left[16 \tau^{C}-\beta(4 \bar{k}+\theta)^{2}\right]\left[36 \tau^{C}-\beta\left(48 \bar{k}^{2}-8 \bar{k} \theta+3 \theta^{2}\right)\right] \\
& +(8 \bar{k}-\theta)\left[16 \tau^{C}-\beta\left(16 \bar{k}^{2}-8 \bar{k} \theta+\theta^{2}\right)\right]\left[36 \tau^{C}-\beta\left(48 \bar{k}^{2}-8 \bar{k} \theta+3 \theta^{2}\right)\right] \\
& +(4 \bar{k}+\theta)\left[24 \tau^{C}-\beta\left(48 \bar{k}^{2}-8 \bar{k} \theta+3 \theta^{2}\right)\right]\left[48 \tau^{C}-\beta\left(48 \bar{k}^{2}-8 \bar{k} \theta+3 \theta^{2}\right)\right] .
\end{aligned}
$$

Since $48 \tau^{C}-\beta\left(48 \bar{k}^{2}-8 \bar{k} \theta+3 \theta^{2}\right)<0$, which implies that $36 \tau^{C}-$ $\beta\left(48 \bar{k}^{2}-8 \bar{k} \theta+3 \theta^{2}\right)<0$ and $24 \tau^{C}-\beta\left(48 \bar{k}^{2}-8 \bar{k} \theta+3 \theta^{2}\right)<0$. Note further that $16 \tau^{C}-\beta(4 \bar{k}+\theta)^{2}>0$ from the definition of $\hat{\delta}_{2}^{P N}$ in (45). Taken together, the first, second and third terms in (B.2) are all positive, so does (B.2), which proves (51).

To get the effect of a change in $\beta$ on the minimum discount factor $\hat{\delta}_{2}^{E A}$ in the ex-ante compliance constraint, we differentiate (45) with respect to $\beta$ to get

$\frac{\partial \hat{\delta}_{2}^{E A}}{\partial \beta}=\frac{(4 \bar{k}+\theta)^{2}\left[-16 \tau^{C}+\beta(-4 \bar{k}+\theta)^{2}\right]^{2}}{32 \tau^{C}\left[16 \tau^{C}-\beta(4 \bar{k}+\theta)^{2}\right]^{2}}+\frac{\beta(-4 \bar{k}+\theta)^{2}\left[-16 \tau^{C}+\beta(-4 \bar{k}+\theta)^{2}\right]}{16 \tau^{C}\left[16 \tau^{C}-\beta(4 \bar{k}+\theta)^{2}\right]}>0$,

whose positive sign immediately follows from $-4 \bar{k}+\theta<0$ and the partici- 
pation constraint $\tau^{C}>\underline{\underline{\tau}}^{C}>(1 / 16) \beta(4 \bar{k}+\theta)^{2}$.

To get the effect of a change in the ex-post compliance constraint we differentiate (46) with respect to $\beta$ to get

$$
\begin{gathered}
\frac{\partial \hat{\delta}_{2}^{P N}}{\partial \beta}=-\frac{\left(-48 \bar{k}^{2}+8 \bar{k} \theta-3 \theta^{2}\right)\left[24 \tau^{C}+\beta\left(-48 \bar{k}^{2}+8 \bar{k} \theta-3 \theta^{2}\right)\right]}{72 \tau^{C}\left[-16 \tau^{C}+\beta(4 \bar{k}+\theta)^{2}\right]} \\
-\frac{\left(-48 \bar{k}^{2}+8 \bar{k} \theta-3 \theta^{2}\right)\left[48 \tau^{C}+\beta\left(-48 \bar{k}^{2}+8 \bar{k} \theta-3 \theta^{2}\right)\right]}{72 \tau^{C}\left[-16 \tau^{C}+\beta(4 \bar{k}+\theta)^{2}\right]} \\
+\frac{(4 \bar{k}+\theta)^{2}\left[24 \tau^{C}+\beta\left(-48 \bar{k}^{2}+8 \bar{k} \theta-3 \theta^{2}\right)\right]\left[48 \tau^{C}+\beta\left(-48 \bar{k}^{2}+8 \bar{k} \theta-3 \theta^{2}\right)\right]}{72 \tau^{C}\left[-16 \tau^{C}+\beta(4 \bar{k}+\theta)^{2}\right]^{2}} .
\end{gathered}
$$

Taking a common denominator of the right-hand side of (B.3) and ignoring the denominator of the resultant expression yields

$$
\begin{aligned}
& \left(48 \bar{k}^{2}-8 \bar{k} \theta+3 \theta^{2}\right)\left[-16 \tau^{C}+\beta(-4 \bar{k}+\theta)^{2}\right]\left[72 \tau^{C}+2 \beta\left(-48 \bar{k}^{2}+8 \bar{k} \theta-3 \theta^{2}\right)\right] \\
& +(4 \bar{k}+\theta)\left[24 \tau^{C}+\beta\left(-48 \bar{k}^{2}+8 \bar{k} \theta-3 \theta^{2}\right)\right]\left[48 \tau^{C}+\beta\left(-48 \bar{k}^{2}+8 \bar{k} \theta-3 \theta^{2}\right)\right]>0 .
\end{aligned}
$$

The positivity of (B.4) implies that (B.3) is negative.

\section{Appendix}

Furthermore, it is seen from (45) and (46) that $\lim _{\tau^{C} \rightarrow \infty} \hat{\delta}_{2}^{E X}=1 / 2$ and $\lim _{\tau^{C} \rightarrow \infty} \hat{\delta}_{2}^{E A}=1$; clearly also $\underline{\underline{\tau}}^{C}>1 / 16 \beta(4 \bar{k}+\theta)^{2}$ for all $\beta>0$. This means that the discontinuity in $(45)$ and $(46)$ at $\tau^{C}=1 / 16 \beta(4 \bar{k}+\theta)^{2}$ does not occur in the relevant domain of $\tau^{C}$. At $\tau^{C}=\underline{\tau}^{C}$ we further find

$$
\begin{aligned}
& \left.\hat{\delta}_{2}^{E A}\right|_{\tau^{C}=\underline{\underline{\tau}}^{C}}=\frac{(3 \theta+4 \bar{k})^{2}(\theta+12 \bar{k})^{2}}{36 \theta^{4}+896 \bar{k}^{2} \theta^{2}+9216 \bar{k}^{4}}, \\
& \left.\hat{\delta}_{2}^{E X}\right|_{\tau^{C}=\underline{\underline{\tau}}^{C}}=\frac{48 \theta \bar{k}(\theta+4 \bar{k})^{2}}{9 \theta^{4}+224 \bar{k}^{2} \theta^{2}+2304 \bar{k}^{4}},
\end{aligned}
$$


so that $\left.\hat{\delta}_{2}^{E A}\right|_{\tau^{C}=\underline{\tau}^{C}}>\left.\hat{\delta}_{2}^{E X}\right|_{\tau^{C}=\underline{\underline{\tau}}^{C}}$. Moreover, it is straightforward to verify not only that $\left.\hat{\delta}_{2}^{E A}\right|_{\tau^{C}=1}<\left.\hat{\bar{\delta}}_{2}^{E X}\right|_{\tau^{C}=1}$, but also that $d \hat{\delta}_{2}^{E A} / d \tau^{C}<0$ and $d \hat{\delta}_{2}^{E X} / d \tau^{C}>0$ at $\tau^{C} \in\left(\underline{\underline{\tau}}^{C}, 1\right)$. To complete the identification of $\delta^{* *}$, we solve $\hat{\delta}_{2}^{E A}=\hat{\delta}_{2}^{E X}$ to get

$$
\begin{aligned}
\widetilde{\tau}^{C}= & \frac{1}{48}\left(6 \beta \theta^{2}+96 \beta \bar{k}^{2}\right) \\
& +\frac{1}{48} \sqrt{\beta^{2}\left[9 \theta^{4}+16 \bar{k}\left(3 \theta^{3}+2 \bar{k}\left(19 \theta^{2}+24 \bar{k}(\theta+3 \bar{k})\right)\right)\right]}>0 .
\end{aligned}
$$

Put together, we can draw the $\hat{\delta}_{2}^{E A}$ and $\hat{\delta}_{2}^{E X}$-curve in Figs.1-3.

\section{References}

Bucovetsky, S. (1991) Asymmetric tax competition. Journal of Urban Economics 30, 167-181.

Brøchner, J., J. Jensen, P. Svensson and P. B. Sørensen (2006) The dilemmas of tax coordination in the enlarged European Union, CESifo Working Paper 1895.

Cardarelli, R., Taugourdeau, E. and J.-P. Vidal (2002) A repeated interactions model of tax competition. Journal of Public Economic Theory 4, $19-38$.

Catenaro, M. and J.-P. Vidal (2006) Implicit tax co-ordination under repeated policy interactions. Recherches Economiques de Louvain $\mathbf{7 2}$, $1-17$.

Devereux, M. P. and P. B. Sørensen (2005) The corporate income tax: International trends and options for fundamental reform, OECD.

Devereux, M., Lockwood, B., and Redoano, M (2008) Do countries compete over corporate tax rates? Journal of Public Economics 92, 1210-1235.

Elitzur, R. and J. Mintz (1996) Transfer pricing rules and corporate tax competition, Journal of Public Economics 60, 401-422. 
Farrell, J. and E. Maskin (1989) Renegotiation in Repeated Games, Games and Economic Behavior 1, 327-360.

Griffith, R., J. Hines, and P. B. Sorensen (2008) International Capital Taxation, Paper prepared for The Mirrlees Review, Reforming the Tax System for the 21st Century (London: Institute for Fiscal Studies).

Haufler, A. (1997) Factor taxation, income distribution, and capital market integration. Scandinavian Journal of Economics 99, 425-446.

Hauler, A. and G. Schjelderup (2000) Corporate tax systems and cross country profit shifting, Oxford Economic Papers 52, 306-325.

Huizinga, H., L. Laeven, and G. Nicodème (2008) Capital structure and international debt shifting, Journal of Financial Economics 88, 80118.

Huizinga, H., and L. Laeven (2008) International profit shifting within multinationals: A multi-country perspective, Journal of Public Economics 92, 1164-1182

Itaya, J., M. Okamura, and C. Yamaguchi (2008) Are regional asymmetries detrimental to tax coordination in a repeated game setting? Journal of Public Economics 92, 2403-2411.

Itaya, J., M. Okamura, and C.Yamaguchi (2010) Partial Tax Coordination in a Repeated Game Setting, CESifo Working Paper 3127.

Kind, H.J., K.M. Midelfart and G. Schjelderup (2005) Corporate tax systems, multinational enterprises, and economic integration, Journal of International Economics 65, 507-521.

Konrad, K. (2008) Mobile tax base as a global common, International Tax and Public Finance 15, 395-414.

Mansori, K.S. and A.J., Weichenrieder (2001) Tax competition and transfer pricing disputes, FinanzArchiv 58, 1-11.

Meade Committee (1978). The structure and reform of direct taxation, Institute for Fiscal Studies, London. 
Mintz, J. and M. Smart (2004) Income shifting, investment and tax competition: theory and evidence from provincial taxation in Canada, Journal of Public Economics 88, 1149-1178.

Nielsen, S.B., P. Raimondos-Møller and G. Schjelderup (2009) Company taxation and tax spillovers: separate accounting versus formula apportionment, European Economic Review (forthcoming).

Peralta, S., and T. van Ypersele (2006) Coordination of capital taxation among asymmetric countries, Regional Science and Urban Economics 56, 708-726.

Peralta, S., Wauthy, X., and van Ypersele, T., 2006, Should countries control international profit shifting?, Journal of International Economics $68,24-37$.

Riedel, N., and M. Runkel (2007). Company tax reform with a water's edge, Journal of Public Economics 91, 1533-1554.

Stähler, F. (1998) Economic Games and Strategic Behaviour: Theory and Application, Edward Elgar, Cheltenham, UK.

Stöwhase, S. (2005) Asymmetric tax competition with profit shifting, Journal of Economics 85, 175-196.

Wildasin, D. E. (1989) Interjurisdictional capital mobility: Fiscal externality and a corrective subsidy, Journal of Urban Economics 25, 193-212.

Wilson, J. D. (1991) Tax competition with interregional differences in factor endowments, Regional Science and Urban Economics 21, 423-451. 